\title{
The Role of Anthracyclines in Acute Myeloid Leukemia Consolidation
}

\author{
JA MIN BYUN ${ }^{1}$, JEONG-OK LEE ${ }^{2}$, KOUNG JIN SUH ${ }^{2}$, JIYUN LEE ${ }^{2}$, DONG-YEOP SHIN ${ }^{1}$, \\ YOUNGIL KOH ${ }^{1}$, JUNSHIK HONG ${ }^{1}$, SOO-MEE BANG ${ }^{2}$, INHO KIM ${ }^{1}$ and SUNG-SOO YOON ${ }^{1}$ \\ ${ }^{1}$ Department of Internal Medicine, Seoul National University College of Medicine, \\ Seoul National University Hospital, Seoul, Republic of Korea; \\ ${ }^{2}$ Department of Internal Medicine, Seoul National University College of Medicine, \\ Seoul National University Bundang Hospital, Seongnam, Republic of Korea
}

\begin{abstract}
Background/Aim: This study was carried out to compare the efficacy and toxicity of consolidation with cytarabine only to consolidation with anthracycline combination in patients with acute myeloid leukemia (AML) achieving complete remission (CR). Patients and Methods: This was a multicenter, retrospective, longitudinal cohort study set between January 2010 and December 2016. Results: Generally, high-dose cytarabine Ied to better survival compared to anthracycline-containing consolidation therapy, as expected. However, for patients not undergoing hematopoietic stem cell transplantation (HSCT), anthracycline use was not necessarily associated with worse survival, depending on the number of consolidation cycles. Postremission, pre-HSCT consolidation with high-dose cytarabine did not negatively affect survival compared to previous reports. For those without FMS-like tyrosine kinase 3 (FLT3) mutation, anthracycline use was associated with a worse survival, but for those with mutation, anthracycline use did not negatively affect survival. Conclusion: For patients who are ineligible for HSCT, selective use of anthracycline consolidation can be a viable option, while for patients with the intention of HSCT, post-remission high-dose cytarabine is a reasonable option in the absence of available donors.
\end{abstract}

To date, the standard treatment of acute myeloid leukemia (AML) comprises induction chemotherapy to induce

Correspondence to: Jeong-Ok Lee, MD, Ph.D., Division of Hematology and Medical Oncology, Department of Internal Medicine, Seoul National University Bundang Hospital, Seoul National University College of Medicine, 82 Gumi-ro, 173 Beongil, Bundang-gu, Seongnam 463-707, Republic of Korea. Tel: +82 317877039, Fax: +82 317874098, e-mail: jeongok77@gmail.com

Key Words: Acute myeloid leukemia, anthracycline, consolidation. complete remission (CR) followed by post-remission treatment in order to improve the duration of long-term remission. In fit patients eligible for standard induction therapy, post-remission treatment after achievement of first CR (CR1) mainly consists of intensive consolidation chemotherapy (1) and allogeneic hematopoietic stem cell transplantation (HSCT) (2). The most widely accepted consolidation chemotherapy consists of repetitive cycles of high-dose cytarabine (HDAC). However, the benefit of additional chemotherapy agents, especially regarding anthracycline combination, remains a controversy. Anthracyclines are a well-known class of drugs active against AML (3) and have remained an integral component of induction chemotherapy for more than three decades. Several studies have congruously suggested a benefit from more intensive anthracycline administration during AML induction therapy (4-7), but the role of anthracyclines during consolidation therapy is poorly defined. Although Bradstock et al. recently reported that an increased cumulative dose of idarubicin during consolidation for adult AML resulted in improved relapse-free survival (RFS) in a phase III study (8), many studies contradicted this finding and advocate HDAC monotherapy (9-11). In addition, post-remission consolidation chemotherapy has not been shown to have a beneficial impact on outcomes after HSCT for patients with AML in CR1 if a donor is readily available (12-14). However, in real-world clinical practice, many patients are subjected to 1-2 additional cycles of consolidation chemotherapy due to lack of donor availability, and in this scenario, optimal consolidation regimens are not well established.

To this end, we carried out this study to compare the efficacy and toxicity of consolidation with cytarabine only with that of anthracycline combination therapy in patients achieving CR1 with uniform induction chemotherapy. Furthermore, we opted to explore the role of post-remission consolidation in patients undergoing HSCT. 


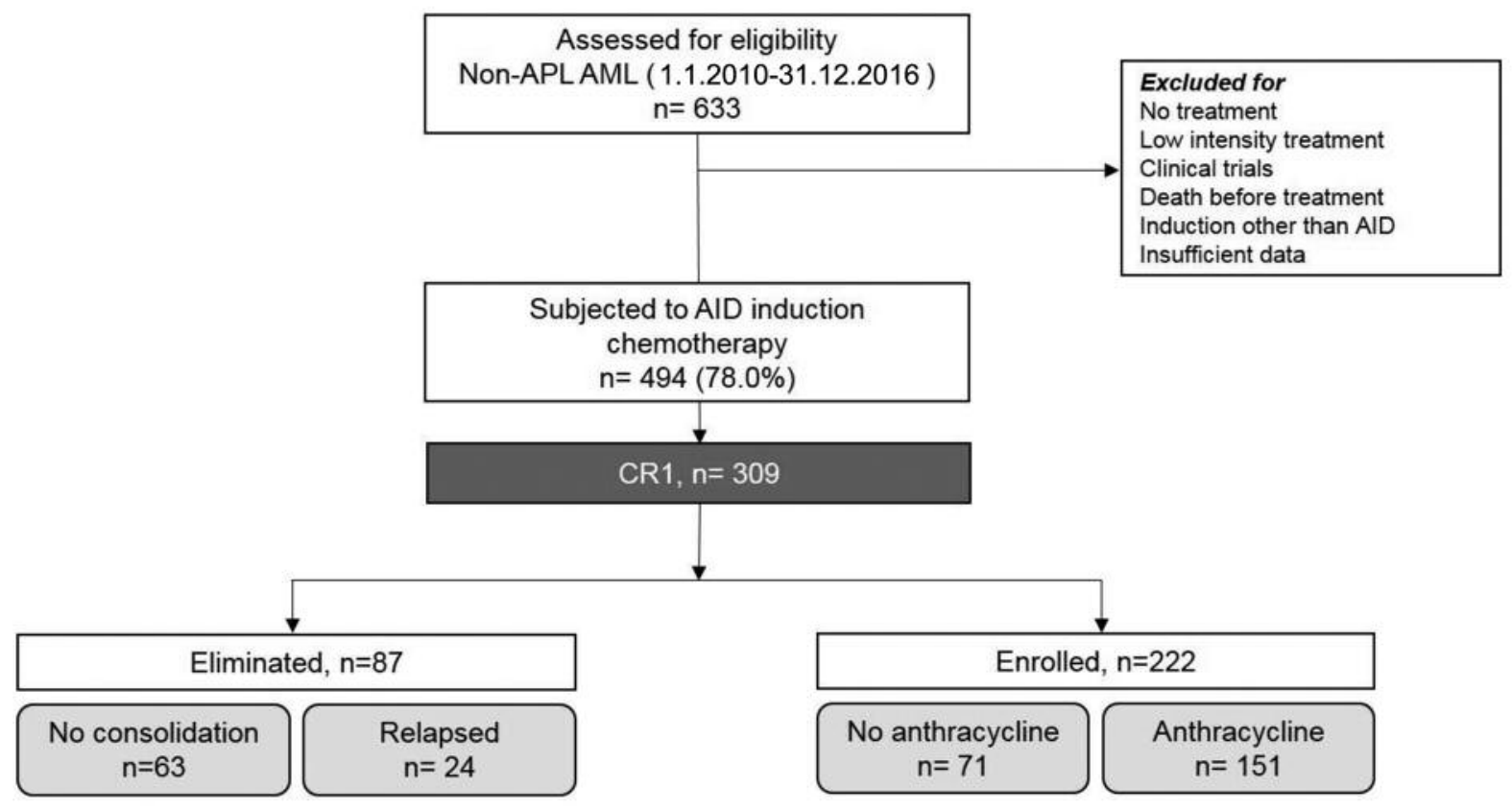

Figure 1. CONSORT diagram.

\section{Patients and Methods}

Study design and patients. This was a multicenter, retrospective, longitudinal cohort study of patients with AML over 16 years old treated at Seoul National University Hospital and Seoul National University Bundang Hospital. The study period was set between January 2010 and December 2016. Patients with AML achieving CR1 with standard $3+7$ induction therapy and receiving at least one cycle of consolidation chemotherapy were included for analysis. Exclusion criteria included patients receiving treatments other than standard $3+7$ induction therapy or no treatment. Patients with acute promyelocytic leukemia were also excluded. During the study period, 633 patients were screened, and after elimination as shown in the CONSORT diagram, a total of 222 patients were deemed eligible (Figure 1). Their medical records were reviewed and analyzed for demographics, baseline disease characteristics, chemotherapy dosing and schedule, factors related to HSCT, response to chemotherapy and HSCT, adverse events, and survival outcomes. This study was conducted according to Declaration of Helsinki and was approved by the Institutional Review Board of the participating hospitals (IRB number B-1509/314-108 for Seoul National University Bundang Hospital; J-1510-025-707 for Seoul National University Hospital).

AML diagnosis and risk stratification. The diagnosis of AML was made according to the WHO Classification of Hematopoietic Neoplasms, which requires identification of $20 \%$ or more leukemia blasts in the bone marrow (15). Secondary AML was defined as AML following myelodysplastic syndrome or myeloproliferative neoplasms confirmed prior to the diagnosis of AML, or AML secondary to proven leukemogenic exposure. Complex karyotype was defined as any karyotype with at least three chromosomal aberrations, regardless of their type and the individual chromosomes involved. Cytogenetic studies were performed at each center, whose satisfactory performance was monitored by a national external quality assurance scheme. Bone marrow cells were cultured for 24 hours then the karyotype was analyzed using the standard Gbanding technique. The karyotypes were constructed and chromosomal abnormalities were reported in accordance with the International System for Human Cytogenetic Nomenclature (16). Prognostic grouping of cytogenetics was performed according to Southwest Oncology Group criteria (17). FMS-related tyrosine kinase 3 (FLT3) internal tandem duplication (ITD) and tyrosine kinase domain (TKD), and nucleophosmin-1 (NPM1) mutations were analyzed using DNA samples obtained at initial diagnosis and multiplex polymerase chain reaction. Risk stratification was mainly based on cytogenetics, and molecular abnormalities for those with available data, according to 2017 National Comprehensive Cancer Network guidelines (18).

Treatment and supportive care. Analyses were conducted overall as well as according to anthracycline use during consolidation (i.e. anthracycline use versus non-use). As mentioned above, all patients received standard $3+7$ induction therapy which consisted of 12 $\mathrm{mg} / \mathrm{m}^{2}$ idarubicin on days $1-3$ plus $100 \mathrm{mg} / \mathrm{m}^{2}$ cytarabine on days 1 7. For anthracycline users, three consolidation regimens were used: (i) Daunorubicin at $45 \mathrm{mg} / \mathrm{m}^{2}$ on days $1-3$ plus $2 \mathrm{~g} / \mathrm{m}^{2}$ cytarabine on days 1-4; (ii) $12 \mathrm{mg} / \mathrm{m}^{2}$ idarubicin on days $1-3$ plus $2 \mathrm{~g} / \mathrm{m}^{2}$ cytarabine on days $1-4$; and (3) HDAC $\left(6 \mathrm{~g} / \mathrm{m}^{2}\right)$ on days $1-3$ plus 12 $\mathrm{mg} / \mathrm{m}^{2}$ idarubicin on days $1-3$. The center's policy for consolidation therapy was daunorubicin/cytarabine $\rightarrow$ idarubicin/cytarabine $\rightarrow$ highdose cytarabine-based regimen. However, the sequence of consolidation regimens and dose reduction was modified at the discretion of the attending physician. For non-anthracycline regimens, consolidation with three cycles of HDAC $\left(3 \mathrm{~g} / \mathrm{m}^{2}\right.$ twice daily over 3 days) was used. 
Table I. Baseline characteristics.

\begin{tabular}{|c|c|c|c|c|c|}
\hline & & \multicolumn{4}{|c|}{ Anthracycline } \\
\hline & & Total & With & Without & $p$-Value \\
\hline & Total & 222 & 151 & 71 & NA \\
\hline \multirow[t]{2}{*}{ Year of diagnosis, n (\%) } & $2010-2013$ & $146(65.8)$ & $133(88.1)$ & $13(18.3)$ & $<0.001$ \\
\hline & 2014-2016 & $76(34.2)$ & $18(23.7)$ & $58(81.7)$ & \\
\hline \multirow[t]{3}{*}{ Age, years } & Median (range) & $51(17-77)$ & $50(18-77)$ & $54(17-77)$ & 0.170 \\
\hline & $<60$ Years, n $(\%)$ & $165(74.3)$ & $118(78.1)$ & $47(66.2)$ & 0.057 \\
\hline & $\geq 60$ Years, n $(\%)$ & $57(25.7)$ & $33(21.9)$ & $24(33.8)$ & \\
\hline Gender, n (\%) & Male & $114(51.4)$ & $82(54.3)$ & $32(45.1)$ & 0.199 \\
\hline \multirow[t]{2}{*}{ Type of leukemia, n (\%) } & De novo & $205(92.3)$ & $140(92.7)$ & $65(91.5)$ & 0.761 \\
\hline & Secondary & $17(7.7)$ & $11(7.3)$ & $6(8.5)$ & \\
\hline \multirow[t]{3}{*}{ Cytogenetic risk, n (\%) } & Low & $51(23.0)$ & $33(21.9)$ & $18(25.3)$ & 0.835 \\
\hline & Intermediate & $140(63.0)$ & $97(64.2)$ & $43(60.6)$ & \\
\hline & High & $31(14.0)$ & $21(13.9)$ & $10(14.1)$ & \\
\hline \multirow{4}{*}{ Combined risk, $\mathrm{n}(\%)^{*}$} & Low & $64(28.8)$ & $40(26.5)$ & $24(33.8)$ & 0.354 \\
\hline & Intermediate & $91(41.0)$ & $61(40.4)$ & $30(42.3)$ & \\
\hline & High & $32(14.4)$ & $22(14.6)$ & $10(14.1)$ & \\
\hline & Unknown & $35(15.8)$ & $28(18.5)$ & $7(9.8)$ & \\
\hline Extramedullary involvement & Yes, n (\%) & $20(9)$ & $9(6.0)$ & $11(15.5)$ & 0.021 \\
\hline \multirow{4}{*}{ Laboratory findings, mean \pm SD } & BM blasts, $\%$ & $60.6 \pm 26.8$ & $61.7 \pm 27.4$ & $58.4 \pm 25.4$ & 0.398 \\
\hline & WBC count, $10^{3} / 1$ & $26,419 \pm 54,205$ & $29,021 \pm 55,132$ & $20,678 \pm 52,038$ & 0.293 \\
\hline & Platelet count, $10^{9} / 1$ & $83.3 \pm 84.2$ & $83.1 \pm 89.2$ & $83.9 \pm 72.6$ & 0.123 \\
\hline & $\mathrm{Hb}, \mathrm{g} / \mathrm{dl}$ & $8.7 \pm 1.9$ & $8.5 \pm 1.7$ & $8.9 \pm 2.1$ & 0.947 \\
\hline
\end{tabular}

NA: Not applicable; BM: bone marrow; WBC: white blood cell; Hb: hemoglobin. *Combined risk refers to risk stratification based on cytogenetic and molecular study results.

Primary fungal prophylaxis with posaconazole at induction was uniformly applied to patients undergoing treatment after April 2015 as reimbursement was granted. Antifungal prophylaxis was not routinely used during consolidation therapy. Secondary fungal prophylaxis was provided to patients with history of fungal infection during induction.

Statistical analysis. The overall survival (OS) and RFS curves were estimated using the Kaplan-Meier method. OS was defined as the time from the date of diagnosis to death from any cause. RFS was derived from the date of CR1 to that of relapse or death from any cause. If patients survived without relapse, RFS was censored on the latest date of follow-up when no relapse was confirmed. Cox proportional hazards model and logistic regression were used to identify significant prognostic indicators for survival. Treatmentrelated mortality (TRM), and treatment-related toxicity were also analyzed. Chemotherapy-related mortality was defined as mortality during consolidation chemotherapy, while HSCT-related mortality was defined as death due to any cause in the absence of relapse or progression of primary disease, including infection, toxicity, and other non-relapse- or disease progression-related causes of death. Time to absolute neutrophil count (ANC) recovery was defined as the interval between the date of starting chemotherapy to the third day when ANC remained over $500 / \mathrm{mm}^{3}$ without granulocyte colony-stimulating factor support. Time to platelet recovery was defined as the interval between chemotherapy start date to the third day when the platelet count remained over $20 \times 10^{9} / 1$ without transfusion. Differences between groups were assessed using Student's $t$-test or one-way analysis of variance for continuous variables, and Pearson chi-square test for categorical variables, as appropriate. All data were analyzed using the Statistical Package for the Social Sciences software (IBM ${ }^{\circledR}$ SPSS ${ }^{\circledR}$ statistics, version 20.0; IBM, Armonk, NY, USA). $p$-Values of less than 0.05 was considered to be statistically significant.

\section{Results}

Patient characteristics. Table I represents the baseline characteristics of all enrolled patients, including 151 prescribed anthracycline and 71 not. The median age was 51 years (range $=17-77$ years) and $92 \%$ had de novo AML. There were no significant differences between the two groups with regards to age, sex, type of leukemia, cytogenetic risk, and baseline laboratory findings. Approximately $20 \%$ of the patients had low-risk AML by cytogenetic risk group, $60 \%$ had intermediate-risk AML and 14\% had high-risk AML. Among 51 patients classified as low risk group, 1 patient with inv(16) had KIT mutation and was thus re-classified as being at intermediate-risk. Among 140 patients classified in the intermediate-risk group, 14 patients were re-classified as low risk group for $\mathrm{NPMI}^{+} / \mathrm{FLT3}^{-}(\mathrm{n}=12)$ or CCAAT enhancer binding protein alpha $(C E B P A)^{+}(\mathrm{n}=2)$. On the other hand, one patient was re-classified as having high risk for harboring FLT3-TKD. The overall incidence of extramedullary disease at the time of AML diagnosis was $9 \%$, with a higher rate in those not given anthracyclines ( 15.5 vs. $6.0 \%, p=0.02)$. The 
Table II. Treatment schema.

\begin{tabular}{|c|c|c|c|c|c|}
\hline & & \multicolumn{4}{|c|}{ Anthracycline } \\
\hline & & Total & With & Without & $p$-Value \\
\hline \multirow{4}{*}{ CX cycles } & Median & 2 & 2 & 2 & 0.220 \\
\hline & $1, \mathrm{n}(\%)$ & $60 \pm 27.0$ & $39 \pm 25.8$ & $21 \pm 29.6$ & \\
\hline & $2, \mathrm{n}(\%)$ & $64 \pm 28.8$ & $49 \pm 32.5$ & $15 \pm 21.1$ & \\
\hline & $3, \mathrm{n}(\%)$ & $98 \pm 44.1$ & $63 \pm 41.7$ & $35 \pm 49.3$ & \\
\hline Induction to CR, days & Mean \pm SD & $31.7 \pm 9.9$ & $31.8 \pm 10.1$ & $31.6 \pm 9.5$ & 0.922 \\
\hline Induction to 1 st $\mathrm{CX}$, days & Mean \pm SD & $62.2 \pm 17.1$ & $65.1 \pm 15.1$ & $55.9 \pm 19.3$ & $<0.001$ \\
\hline Upfront HSCT, n (\%) & Frequency & $66(29.7)$ & $39(25.8)$ & $27(38.0)$ & 0.064 \\
\hline \multirow[t]{3}{*}{ HSCT Donor, n (\%) } & Matched related & $37(56.1)$ & $22(56.4)$ & $15(55.6)$ & 0.468 \\
\hline & Matched unrelated & $16(24.2)$ & $11(28.2)$ & $5(18.5)$ & \\
\hline & Other* & $13(19.7)$ & $6(15.4)$ & $7(25.9)$ & \\
\hline \multirow[t]{2}{*}{ HSCT Conditioning, $\mathrm{n}(\%)$} & Myeloablative & $14(21.1)$ & $9(23.1)$ & $5(18.5)$ & 0.656 \\
\hline & Reduced intensity & $52(78.8)$ & $30(76.9)$ & $22(81.5)$ & \\
\hline
\end{tabular}

CX: Consolidation therapy; CR: complete remission; HSCT: hematopoietic stem cell transplantation; NA: not applicable. *Including mismatched related donors and cord blood.

sites involved were: Lymph nodes in six, brain in four, cerebrospinal fluid in three, soft tissue in two, pleural effusion in one, liver in one, and other solid organ involvement in three.

Treatment schema of consolidation treatment. Both groups received a median of two cycles of consolidation chemotherapy (Table II). There were 60 patients $(27.0 \%)$ who received only one cycle of consolidation chemotherapy (Table II). Among them 46 (76.7\%) were subjected to upfront HSCT (Table III). Among 14 patients who did not undergo HSCT, reasons for only receiving one cycle of consolidation chemotherapy were as follows: Death during consolidation in two; hepatitis B reactivation in one; patient refusal in 11. Approximately $30 \%$ of patients underwent upfront HSCT and the rate was higher in those not receiving anthracycline, although not without statistical significance $(38.0 \%$ vs. $29.7 \%$, $p=0.064$ ). Among patients with high cytogenetic risk, $45 \%$ underwent upfront HSCT, with a comparable rate between the two groups (no anthracycline vs. anthracycline, $50 \%$ vs. $43 \%$ ). Seventeen patients with high cytogenetic risk did not undergo HSCT because they were too old for (i.e. older than 65 years old at diagnosis; $n=5)$, had no suitable donors $(n=7)$, refused HSCT $(n=2)$, died during consolidation $(n=2)$, or were transferred to another hospital $(n=1)$.

The median number of cycles of consolidation chemotherapy before upfront HSCT was one in both groups. There was no difference between those treated with anthracycline and those not with regard to time to CR (31.8 vs. 31.6 days, respectively, $p=0.922$ ), but those receiving anthracycline were subjected to delay of by approximately 9 days in delivery of consolidation therapy (time interval between induction to first consolidation therapy: $65.1 \mathrm{vs} .55 .9$ days, respectively, $p<0.001)$.
Table IV presents the cytarabine dose delivered to patients in each group during consolidation. For those not administered anthracycline, there were 21 patients who received one cycle of consolidation, 15 patients received two cycles, and 35 patients received three cycles. For those given anthracycline, there were 39 patients receiving one cycle of consolidation, 49 receiving two cycles and 63 patients receiving three cycles. More cytarabine was delivered during the third cycle of consolidation, as per the center's policy on consolidation treatment schema. When compared, more cytarabine was delivered to those not given anthracycline during the first consolidation (mean dose $15.9 \mathrm{~g} / \mathrm{m}^{2}$ vs. $8.0 \mathrm{~g} / \mathrm{m}^{2}$ for those not, $p<0.001$ ) and the second (mean dose $12.9 \mathrm{~g} / \mathrm{m}^{2} v s .9 .2 \mathrm{~g} / \mathrm{m}^{2}, p<0.001$ ). There were no differences in the cytarabine dose delivered during the third consolidation $(p=0.538)$. The dose of idarubicin delivered to anthracycline users is presented in Table V.

Adverse events during consolidation chemotherapy. As shown in Table VI, there were more deaths in those treated with anthracycline, but there were no differences in TRM between the two groups. The most common cause of TRM during consolidation was fungal infection $(n=7)$. There was one patient who died of intracranial hemorrhage associated with thrombocytopenia, and one who died of ischemic colitis. There were seven mortalities related to upfront HSCT. Three patients died of infection, two patients due to engraftment failure, and two of complicated graft-versus-host disease.

There were more bacterial infection events in those given anthracyclines during the first consolidation (Table VI). As for fungal infection, there were no differences between the two groups. The majority of those not receiving anthracycline received primary fungal prophylaxis with posaconazole during induction chemotherapy (Table VII). Anthracycline use was 
Table III. Characteristics of patients undergoing hematopoietic stem cell transplantation.

\begin{tabular}{|c|c|c|c|c|c|}
\hline & & \multicolumn{4}{|c|}{ Anthracycline } \\
\hline & & Total & With & Without & $p$-Value \\
\hline & Total & 66 & 39 & 27 & NA \\
\hline Age, years & Median (range) & $46(18-63)$ & $46(18-63)$ & $46(21-63)$ & 0.772 \\
\hline \multirow[t]{3}{*}{ Cytogenetic risk, n (\%) } & Low & $9(13.6)$ & $2(5.1)$ & $7(25.9)$ & 0.086 \\
\hline & Intermediate & $43(65.2)$ & $28(71.8)$ & $15(55.6)$ & \\
\hline & High & $14(21.2)$ & $9(23.1)$ & $5(18.5)$ & \\
\hline CR1 to HSCT, days & Median (range) & $103.5(17-282)$ & $109(62-276)$ & $99(17-282)$ & 0.068 \\
\hline
\end{tabular}

CR1: First complete remission; HSCT: hematopoietic stem cell transplantation; NA: not applicable.

Table IV. Cytarabine dose according to consolidation step and number of consolidations. Data are mean/median (range).

\begin{tabular}{|c|c|c|c|c|c|}
\hline \multirow[b]{2}{*}{ Anthracycline } & \multirow[b]{2}{*}{ Consolidation ${ }^{\#}$} & \multicolumn{3}{|c|}{ Consolidation } & \multirow[b]{2}{*}{ Total } \\
\hline & & 1 st & 2nd & $3 \mathrm{rd}$ & \\
\hline \multirow[t]{5}{*}{ Without } & $1(\mathrm{~N}=21)$ & $15.9 / 18.0(8.0-18.0)$ & NA & NA & $15.9 / 18(8.0-18.0)$ \\
\hline & $2(\mathrm{~N}=15)$ & $12.5 / 15.0(8.0-18.0)$ & $12.9 / 13.9(4.0-18.0)$ & NA & $25.5 / 29.0(16.0-36.0)$ \\
\hline & $3(\mathrm{~N}=35)$ & $14.6 / 15.0(7.5-18.0)$ & $14.2 / 12.0(9.0-18.0)$ & $13.5 / 12.0(4.0-18.0)$ & $42.5 / 36(25.5-54.0)$ \\
\hline & Per step & $14.8 / 15.0(7.5-18.0)$ & $13.8 / 12.0(4.0-18.0)$ & $13.5 / 12.0(4.0-18.0)$ & NA \\
\hline & & $(\mathrm{N}=71)$ & $(\mathrm{N}=50)$ & $(\mathrm{N}=35)$ & NA \\
\hline \multirow[t]{5}{*}{ With } & $1(\mathrm{~N}=39)$ & $8.0 / 8.0(8.0-8.0)$ & NA & NA & $8.0 / 8.0(8.0-8.0)$ \\
\hline & $2(\mathrm{~N}=49)$ & $7.6 / 8.0(3.0-8.0)$ & 7.8/8.0 (0.14-18.0) & NA & $15.4 / 16(7.0-26.0)$ \\
\hline & $3(\mathrm{~N}=63)$ & $8.2 / 8.0(4.0-18.0)$ & $9.2 / 8.0(4.0-18.0)$ & $13.0 / 12.0(2.0-18.0)$ & $30.5 / 32.0(12.0-32.0)$ \\
\hline & Per step & $7.9 / 8.0(3.0-18.0)$ & 8.6/8.0 (0.14-18.0) & $13.0 / 12.0(2.0-18.0)$ & NA \\
\hline & & $(\mathrm{N}=151)$ & $(\mathrm{N}=112)$ & $(\mathrm{N}=63)$ & NA \\
\hline
\end{tabular}

\#Number; NA: not applicable.

Table V. Idarubicin* dose according to consolidation step and number of consolidation for anthracycline users. Data are mean/median (range).

\begin{tabular}{lcccc}
\hline & \multicolumn{4}{c}{ Consolidation } \\
\cline { 2 - 4 } Cosolidation\# & 1 st & 2nd & 3rd & Total \\
\hline $1(\mathrm{~N}=39)$ & $30.0 / 27(27.0-36.0)$ & $\mathrm{NA}$ & $\mathrm{NA}$ & $65.3 / 63.0(57.0-72.0)$ \\
$2(\mathrm{~N}=49)$ & $28.9 / 27(12.0-36.0)$ & $30.1 / 36(0-36.0)$ & $\mathrm{NA}$ & $93.2 / 99.0(54.0-108.0)$ \\
$3(\mathrm{~N}=63)$ & $29.9 / 27.0(0-36.0)$ & $31.3 / 36.0(0-36.0)$ & $20.9 / 27.0(0-36.0)$ & $117.6 / 126(60.0-144.0)$ \\
Per step & $29.6 / 27.0(0-36.0)$ & $30.8 / 36(0-36.0)$ & $20.9 / 27.0(0-36.0)$ & NA \\
& $(\mathrm{N}=151)$ & $(\mathrm{N}=112)$ & $(\mathrm{N}=63)$ & \\
\hline
\end{tabular}

\#Number; NA: not applicable. ${ }^{*}$ Conversion rate: daunorubicin=1, idarubicin=5, mitoxantrone=4.

also associated with longer hospital stay, longer time to ANC recovery and longer time to platelet recovery (Table VI). This trend was most prominently observed during the second cycle of consolidation chemotherapy.

Treatment schema after relapse. There were more relapses in those administered anthracyclines $(62.3 \%$ vs. $43.7 \%$, $p=0.009$ ). After relapse, $84.0 \%$ of the patients underwent salvage treatment: $80.8 \%$ of the patients received either standard re-induction or low-intensity chemotherapy, while $3.2 \%$ of the patients underwent salvage HSCT without reinduction (Table VIII). There were no differences in the rates of re-induction, salvage HSCT, and CR2 achievement between those administered anthracycline and those not. 
Table VI. Adverse events during consolidation.

\begin{tabular}{|c|c|c|c|c|c|}
\hline \multirow[b]{2}{*}{ Event } & & \multicolumn{4}{|c|}{ Anthracycline } \\
\hline & & Total & With & Without & $p$-Value \\
\hline \multirow[t]{7}{*}{ Death } & Any cause, n (\%) & $98(44.1)$ & $83(55.0)$ & $15(21.1)$ & $<0.001$ \\
\hline & Before 1st relapse, n (\%) & $22(9.9)$ & $17(11.3)$ & $5(7.0)$ & 0.316 \\
\hline & TRM, $\mathrm{n}$ & & & & \\
\hline & During CX & 16 & 12 & 4 & \\
\hline & Related to CX & 9 & 7 & 2 & \\
\hline & Related to upfront HSCT & 7 & 5 & 2 & \\
\hline & Other cause, $\mathrm{n}$ & - & 6 & 5 & 1 \\
\hline \multirow[t]{3}{*}{ Bacteremia, n (\%) } & 1st $\mathrm{CX}(\mathrm{N}=222)$ & $80(36.0)$ & $62(41.1)$ & $18(25.4)$ & 0.023 \\
\hline & 2nd $\mathrm{CX}(\mathrm{N}=162)$ & $78(48.1)$ & $57(50.9)$ & $21(42.0)$ & 0.295 \\
\hline & 3 rd $\mathrm{CX}(\mathrm{N}=98)$ & $38(38.8)$ & $24(38.1)$ & $14(40.0)$ & $>0.99$ \\
\hline \multirow{3}{*}{ Fungal infection, $\mathrm{n}(\%)$} & 1st $\mathrm{CX}(\mathrm{N}=222)$ & $12(5.4)$ & $10(6.6)$ & $2(2.8)$ & 0.242 \\
\hline & 2nd $\mathrm{CX}(\mathrm{N}=162)$ & $13(8.0)$ & $12(10.7)$ & $1(2.0)$ & 0.059 \\
\hline & $3 \operatorname{rd} \mathrm{CX}(\mathrm{N}=98)$ & $5(5.1)$ & $4(6.3)$ & $1(6.3)$ & 0.452 \\
\hline \multirow[t]{3}{*}{ Mean hospitalization \pm SD, days* } & 1st $\mathrm{CX}(\mathrm{N}=222)$ & $27.0 \pm 11.3$ & $28.3 \pm 13.1$ & $24.1 \pm 5.1$ & 0.009 \\
\hline & 2nd $\mathrm{CX}(\mathrm{N}=162)$ & $32.3 \pm 13.4$ & $35.9 \pm 14.5$ & $24.3 \pm 4.7$ & $<0.001$ \\
\hline & 3rd CX $(\mathrm{N}=98)$ & $28.4 \pm 11.3$ & $30.5 \pm 13.4$ & $24.6 \pm 3.4$ & 0.012 \\
\hline \multirow{3}{*}{$\begin{array}{l}\text { Mean time to ANC } \\
\text { recovery } \pm S D \text {, days }\end{array}$} & 1st $\mathrm{CX}(\mathrm{N}=222)$ & $18.6 \pm 5.6$ & $18.4 \pm 5.8$ & $18.9 \pm 5.3$ & 0.567 \\
\hline & 2nd $\mathrm{CX}(\mathrm{N}=162)$ & $22.9 \pm 10.4$ & $24.9 \pm 11.1$ & $17.4 \pm 4.5$ & $<0.001$ \\
\hline & $3 \operatorname{rd~CX}(\mathrm{N}=98)$ & $21.3 \pm 8.1$ & $21.9 \pm 9.6$ & $20.2 \pm 4.4$ & 0.322 \\
\hline \multirow{3}{*}{$\begin{array}{l}\text { Mean time to platelet } \\
\text { recovery } \pm S D \text {, days }\end{array}$} & 1st $\mathrm{CX}(\mathrm{N}=222)$ & $20.4 \pm 8.7$ & $21.0 \pm 9.6$ & $18.7 \pm 5.1$ & 0.046 \\
\hline & 2nd $\mathrm{CX}(\mathrm{N}=162)$ & $26.4 \pm 15.4$ & $29.6 \pm 16.6$ & $17.4 \pm 4.5$ & $<0.001$ \\
\hline & 3 rd $\mathrm{CX}(\mathrm{N}=98)$ & $23.4 \pm 15.3$ & $24.7 \pm 16.3$ & $20.6 \pm 12.8$ & 0.212 \\
\hline
\end{tabular}

TRM: Treatment-related mortality; HSCT: hematopoietic stem cell transplantation; COD: cause of death; CX: consolidation therapy; ANC: absolute neutrophil count. *Unknown COD $(\mathrm{N}=5)$, death from secondary malignancy $(\mathrm{N}=1)$. Time to ANC recovery refers to the time interval between chemotherapy start to the third day of ANC $>500 / \mathrm{mm}^{3}$ without granulocyte colony-stimulating factor support. Time to platelet recovery refers to the time interval between chemotherapy start to the third day of platelet count $>20 \times 10^{9} / 1$ without transfusion.

Table VII. Fungal prophylaxis.

\begin{tabular}{|c|c|c|c|c|}
\hline & \multicolumn{4}{|c|}{ Anthracycline, n (\%) } \\
\hline & Total & With & Without & $\begin{array}{c}p \text {-Value } \\
\text { Total }\end{array}$ \\
\hline Diagnosed after April 2015* & $42(18.9)$ & $2(1.3)$ & $40(56.3)$ & $<0.001$ \\
\hline During induction $(\mathrm{N}=222)$ & $42(18.9)$ & $2(1.3)$ & $40(56.3)$ & $<0.001$ \\
\hline During 1st consolidation $(\mathrm{N}=222)$ & $12(5.4)$ & $10(6.6)$ & $2(2.8)$ & 0.242 \\
\hline During 2 nd consolidation $(\mathrm{N}=162)$ & $17(10.6)$ & $15(13.5)$ & $2(4.0)$ & 0.069 \\
\hline During 3rd consolidation $(\mathrm{N}=98)$ & $14(14.3)$ & $12(19.0)$ & $2(5.7)$ & 0.071 \\
\hline
\end{tabular}

*The date of reimbursement issued for primary posaconazole prophylaxis for patients undergoing induction.

Survival outcomes. The median follow-up duration for the whole cohort was 31 months (34.6 months for the anthracycline group and 29 months for the nonanthracycline group), the estimated 3-year OS rate was $61.3 \%$ and RFS was $34.9 \%$. The RFS was significantly shorter in those administered anthracyclines (median $=13.5$ vs. 35.5 months, $p=0.014$; Figure 2A). On multivariate analysis, anthracycline administration was identified as significant negative prognostic factor for RFS [hazard ratio
$(\mathrm{HR})=1.732,95 \%$ confidence intervaI $(\mathrm{CI})=1.155-2.598$, $p=0.008$; Table IX]. High cytogenetic risk and no upfront HSCT were also recognized as prognostic factors for poorer RFS.

The OS was also significantly shorter in those administered anthracyclines (median $=38.7 v s$. 62.1 months, $p=0.001$; Figure 2A). On multivariate analysis, anthracycline use, age, and cytogenetic risk group were identified as prognostic factors for OS (Table IX). 
Table VIII. Treatment schema after relapse.

\begin{tabular}{|c|c|c|c|c|}
\hline & \multicolumn{4}{|c|}{ Anthracycline, n (\%) } \\
\hline & Total & With & Without & $p$-Value \\
\hline Actual relapse & $125(56.3)$ & $94(62.3)$ & $31(43.7)$ & 0.009 \\
\hline Treatment after relapse & & & & 0.540 \\
\hline Chemotherapy & $101(80.8)$ & $74(78.7)$ & $27(87.1)$ & \\
\hline Standard re-induction & 97 & 71 & 26 & \\
\hline Low intensity chemotherapy* & 4 & 3 & 1 & \\
\hline HSCT without induction chemotherapy & $4(3.2)$ & $3(3.2)$ & $1(3.2)$ & \\
\hline No treatment & $20(16.0)$ & $17(18.1)$ & $3(9.7)$ & \\
\hline CR2 achievement Yes & $70(57.9)$ & $52(57.1)$ & $18(60.0)$ & 0.950 \\
\hline HSCT $\quad$ Yes & $57(47.1)$ & $44(48.4)$ & $13(43.3)$ & 0.633 \\
\hline Salvage & $50(87.7)$ & $39(88.6)$ & $11(84.6)$ & \\
\hline $2 \mathrm{nd}^{\#}$ & $7(12.3)$ & $5(11.4)$ & $2(15.4)$ & \\
\hline
\end{tabular}

HSCT: Hematopoietic stem cell transplantation; CR2: second complete remission. *Salvage chemotherapy included hypomethylating agents and low-dose cytarabine treatment. "Refers to the patients who underwent upfront HSCT.

Table IX. Univariate and multivariate analysis using Cox regression for relapse-free survival (RFS) and overall survival (OS).

\begin{tabular}{|c|c|c|c|c|c|c|c|c|}
\hline & \multicolumn{4}{|c|}{ RFS } & \multicolumn{4}{|c|}{ OS } \\
\hline & \multicolumn{2}{|c|}{ Univariate analysis } & \multicolumn{2}{|c|}{ Multivariate analysis } & \multicolumn{2}{|c|}{ Univariate analysis } & \multicolumn{2}{|c|}{ Multivariate analysis } \\
\hline & HR $(95 \% \mathrm{CI})$ & $p$-Value & HR $(95 \%$ CI $)$ & $p$-Value & HR $(95 \%$ CI $)$ & $p$-Value & HR $(95 \% \mathrm{CI})$ & $p$-Value \\
\hline \multicolumn{9}{|l|}{ Age } \\
\hline$\geq 60$ vs. $<60$ Years & $1.549(1.080-2.222)$ & 0.018 & $1.426(0.975-2.084)$ & 0.067 & $1.777(1.158-2.727)$ & 0.009 & $1.966(1.272-3.036)$ & 0.002 \\
\hline \multicolumn{9}{|l|}{ Cytogenetic risk } \\
\hline High vs. non-high & $2.254(1.466-3.467)$ & $<0.001$ & $2.459(1.581-3.824)$ & $<0.001$ & $2.335(1.449-3.763)$ & $<0.001$ & $2.344(1.451-3.787)$ & 0.001 \\
\hline \multicolumn{9}{|l|}{ Anthracycline } \\
\hline Yes vs. no & $1.615(1.095-2.382)$ & 0.016 & $1.732(1.155-2.598)$ & 0.008 & $2.438(1.400-4.246)$ & 0.002 & $2.849(1.621-5.009)$ & $<0.001$ \\
\hline \multicolumn{9}{|l|}{ Upfront HSCT } \\
\hline Yes vs.no & $0.538(0.359-0.807)$ & 0.003 & $0.573(0.377-0.869)$ & 0.009 & $0.881(0.565-1.372)$ & 0.575 & NA & NA \\
\hline
\end{tabular}

HR: Hazard ratio; CI: confidence interval; HSCT: hematopoietic stem cell transplantation; NA: not applicable.

When patients were further divided into four groups according to anthracycline use and upfront HSCT (Figure 2B), those undergoing HSCT who had not received anthracycline had the longest RFS (median RFS not reached), followed by those treated with anthracycline undergoing HSCT (26.6 months, $p=0.054)$ compared to those not treated with anthracycline undergoing HSCT, those not treated with anthracycline and not receiving HSCT (17.9 months, $p=0.015$ ) and those treated with anthracycline not receiving HSCT (12.7 months, $p=0.001)$. Interestingly, OS patterns were different from RFS patterns, and those not administered anthracyclines had better survival compared to those receiving them, regardless of history of upfront HSCT. Among those not given anthracyclines, there was no difference with regards to OS between those undergoing upfront HSCT and those not $(p>0.99)$; similarly, in those given anthracycline, there was also no difference in OS according to HSCT $(p=0.885)$.

\section{Discussion}

Generally, HDAC led to better survival compared to anthracycline-containing consolidation, as expected. However, we noted some interesting findings with anthracycline use during consolidation. Namely, we recognized that the use of anthracycline has different effects in patients undergoing upfront HSCT versus those not undergoing HSCT. For patients who ultimately underwent HSCT after receiving post-remission consolidative chemotherapy, anthracycline use negatively affected the outcomes. However, for patients who did not undergo HSCT, anthracycline use was not necessarily associated with worse RFS (17.9 months without anthracycline vs. 12.7 

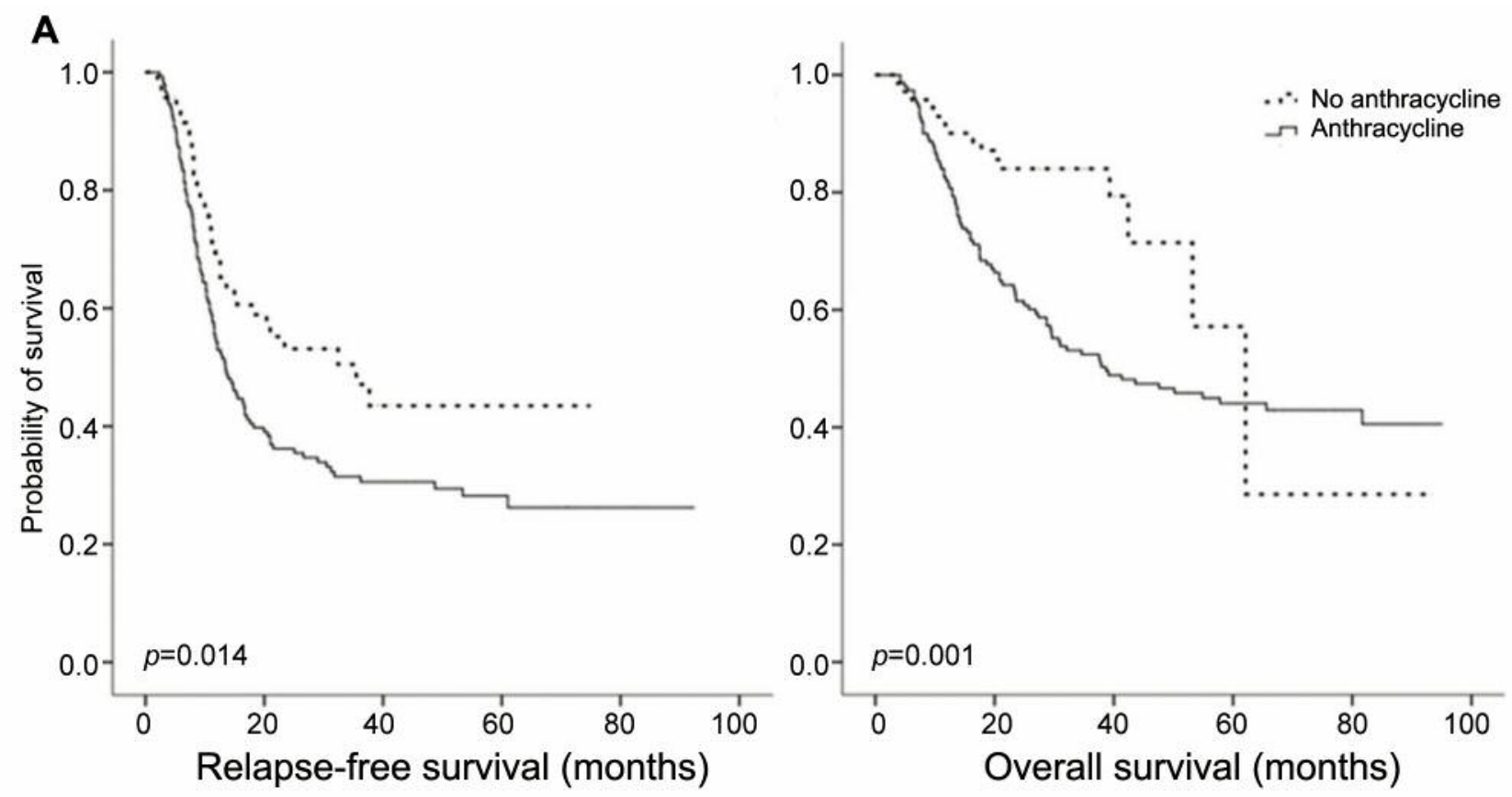

B
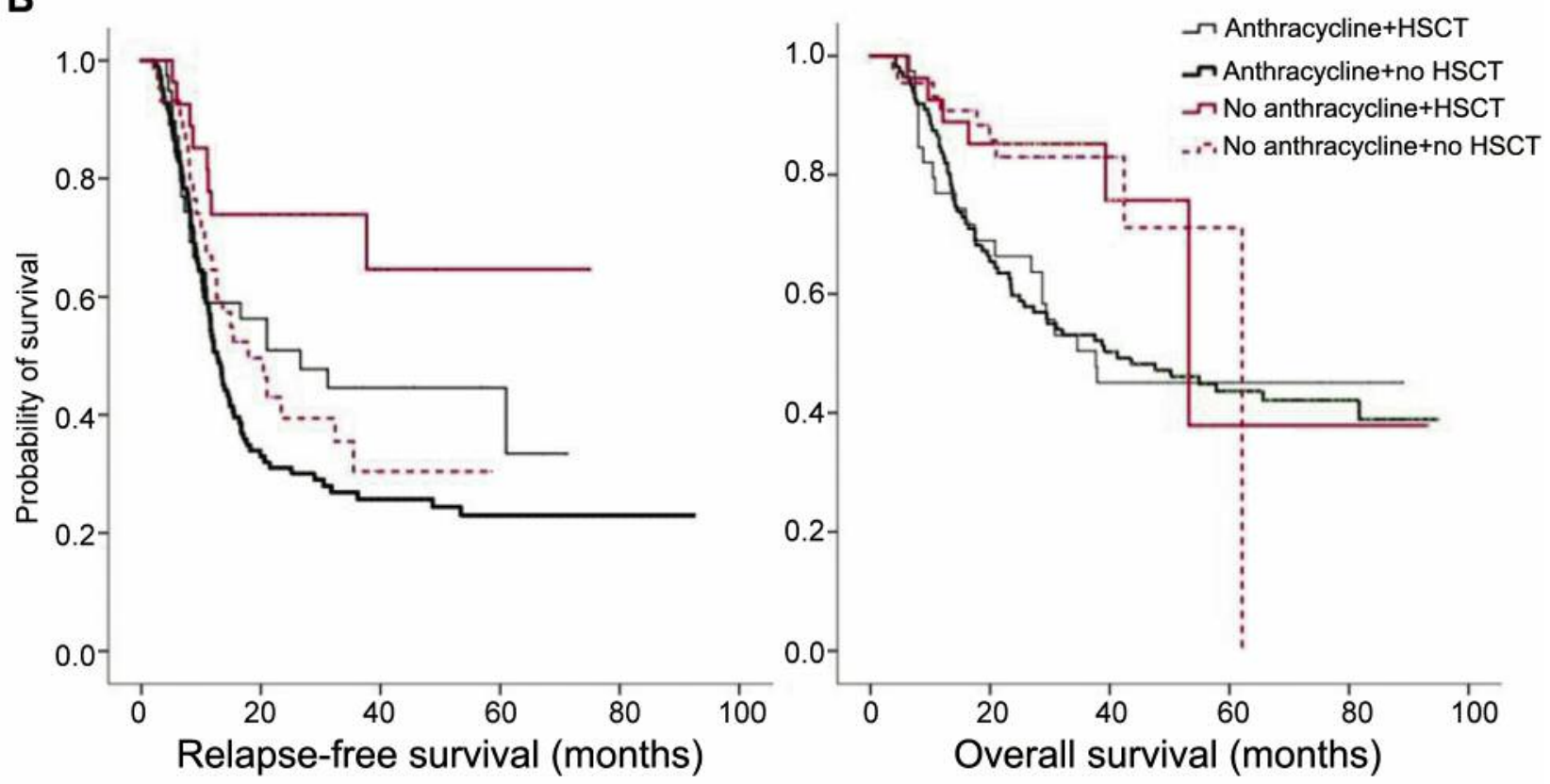

Figure 2. Relapse-free survival and overall survival according to anthracycline use (A) and anthracycline use and upfront hematopoietic stem cell transplantation $(B)$.

months with anthracycline, $p=0.197$; Figure 2B). When the number of consolidation was considered, patients who received three cycles of consolidation therapy had longer RFS (median=17.6 months) than those who received only one cycle (median=5.7 months), as expected. Among patients who received only one cycle of consolidation therapy, those not treated with anthracyclines had better RFS than those who were (median=7.8 vs. 5.2 months, respectively, $p=0.047$ ). Interestingly however, for patients receiving two cycles of consolidation, those receiving anthracycline had slightly better RFS (median=6.9 vs. 11.6 months, respectively, $p=0.102$ ) and, for patients receiving all three cycles of consolidation therapy there were no differences in RFS (median=16.7 vs. 21 months, respectively, $p=0.414$ ). Based on these findings, for patients 
without planning for HSCT, anthracycline-based consolidation can be used as an alternative option for those who cannot tolerate HDAC due to side-effects or who cannot complete all three cycles of consolidation for whatever reason.

Another interesting observation is on OS and its prognostic factors. As mentioned above, for patients not undergoing HSCT, anthracycline use seemingly had little effect on RFS. However, for the same subgroup of patients, those treated with anthracycline had significantly worse OS (Figure 2B). Although the rates of CR2 achievement and salvage HSCT were not different between the two groups, we speculate that this discrepancy is due to the quality of CR2. Given that those receiving anthracycline were more recently treated and thus had access to better salvage chemotherapy options and supportive care, these patients might have had a deeper response and longer second RFS. This might also explain why upfront HSCT was not a prognostic factor for OS (Table IX) in our cohort.

Regarding the issue of post-remission pre-HSCT consolidation therapy, only a limited amount of data is available to help guide this decision. Since all patients enrolled in our study received at least one cycle of consolidation therapy before HSCT, we cannot make a direct comparison with patients undergoing HSCT without consolidation. However, survival outcomes of our patients (estimated 3-year OS of $60.7 \%$, RFS rate of $51.9 \%$ for patients undergoing upfront HSCT) were comparable to those of previous studies $(12,19)$, and based on this we can assume that consolidation at least did not negatively affect the survival outcomes of the patients. Especially since most of our patients underwent HSCT with reduced intensity conditioning, some might have benefited from potential additive effects of post-remission consolidation in the absence of readily available donors. Furthermore, our results suggest that if upfront HSCT is delayed and consolidation is needed, HDAC seems to be a reasonable choice. Although we cannot suggest a definite cutoff for the optimal cumulative dose of cytarabine, adequate delivery of cytarabine seems to play an important role in survival outcomes, and those who cannot tolerate HDAC should receive additional chemo-agent(s) as compensation.

Besides the obvious pitfall of being a retrospective study, another major limitation of our study is the lack of molecular and genetic data. However, there were 112 patients with FLT3 mutation status available, and the role of anthracycline-based consolidation was evaluated in this subgroup of patients. Out of 91 patients without FLT3 mutation, 56 were treated with anthracycline. When survival was compared, those not treated with anthracycline had longer RFS (median=35.5 vs. 15.5 months, respectively, $p=0.088$ ) and significantly longer OS (81.7 vs. 41.3 months, respectively, $p=0.009$ ). On the other hand, there were 21 patients with FLT3 mutation and as whole, survival of these patients was significantly shorter compared to patients without FLT3 mutation. Interestingly, there were no differences according to anthracycline therapy with regards to
RFS (9.6 vs. 6.2 months, respectively, $p=0.437)$ and OS (30.8 vs. 12.4 months, respectively, $p=0.605)$. Since there were only 10 treated with anthracycline and 11 not, the number of patients was too small to draw definitive conclusions, but the role of daunorubicin in this subset of patients deserves attention not only during induction (20), but also during consolidation.

We feel that one of the strengths of our study is how accurately it represents real-world practice, where patients are subjected to at least one cycle of consolidation regardless of intended HSCT due to many barriers, including a lack of readily available donors. For patients assigned to HSCT with reduced intensity conditioning, bridging HDAC consolidation may have an additive role in better RFS. Finally, for patients who are ineligible for HSCT, selective use of anthracycline consolidation seems to be a viable option.

\section{Conflicts of Interest}

There are no conflicts of interest to disclose regarding this study.

\section{Authors' Contributions}

Design of the study: Ja Min Byun, Jeong-Ok Lee. Patient enrollment and data collection: All Authors. Data analysis: Ja Min Byun, Koung Jin Suh, Jeong-Ok Lee. Wrote the article: Ja Min Byun, Jeong-Ok Lee. Revised the article: All Authors.

\section{Acknowledgements}

The results of this study have been submitted to the 61th American Society of Hematology Annual Meeting \& Exposition, Orlando, FL, USA.

\section{References}

1 Cassileth PA, Lynch E, Hines JD, Oken MM, Mazza JJ, Bennett JM, McGlave PB, Edelstein M, Harrington DP, O'Connell MJ: Varying intensity of postremission therapy in acute myeloid leukemia. Blood 79: 1924-1930, 1992. PMID: 1562720.

2 Ringden O, Pavletic SZ, Anasetti C, Barrett AJ, Wang T, Wang D, Antin JH, Di Bartolomeo P, Bolwell BJ, Bredeson C, Cairo MS, Gale RP, Gupta V, Hahn T, Hale GA, Halter J, Jagasia M, Litzow MR, Locatelli F, Marks DI, McCarthy PL, Cowan MJ, Petersdorf EW, Russell JA, Schiller GJ, Schouten H, Spellman S, Verdonck LF, Wingard JR, Horowitz MM and Arora M: The graft-versusleukemia effect using matched unrelated donors is not superior to HLA-identical siblings for hematopoietic stem cell transplantation. Blood 113: 3110-3118, 2009. PMID: 19059878. DOI: 10.1182/blood-2008-07-163212

3 Tallman MS, Gilliland DG and Rowe JM: Drug therapy for acute myeloid leukemia. Blood 106: 1154-1163, 2005. PMID: 15870183. DOI: 10.1182/blood-2005-01-0178

4 Fernandez HF, Sun Z, Yao X, Litzow MR, Luger SM, Paietta EM, Racevskis J, Dewald GW, Ketterling RP, Bennett JM, Rowe JM, Lazarus HM and Tallman MS: Anthracycline dose intensification in acute myeloid leukemia. N Engl J Med 361: 1249-1259, 2009. PMID: 19776406. DOI: 10.1056/NEJMoa0904544 
5 Luskin MR, Lee JW, Fernandez HF, Abdel-Wahab O, Bennett JM, Ketterling RP, Lazarus HM, Levine RL, Litzow MR, Paietta EM, Patel JP, Racevskis J, Rowe JM, Tallman MS, Sun Z and Luger SM: Benefit of high-dose daunorubicin in AML induction extends across cytogenetic and molecular groups. Blood 127: 1551-1558, 2016. PMID: 26755712. DOI: 10.1182/blood-2015-07-657403

6 Lee JH, Joo YD, Kim H, Bae SH, Kim MK, Zang DY, Lee JL, Lee GW, Lee JH, Park JH, Kim DY, Lee WS, Ryoo HM, Hyun MS, Kim HJ, Min YJ, Jang YE, Lee KH; Cooperative Study Group A for Hematology: A randomized trial comparing standard versus high-dose daunorubicin induction in patients with acute myeloid leukemia. Blood 118: 3832-3841, 2011. PMID: 21828126. DOI: 10.1182/blood-2011-06-361410

7 Burnett AK, Russell NH, Hills RK, Kell J, Cavenagh J, Kjeldsen L, McMullin MF, Cahalin P, Dennis M, Friis L, Thomas IF, Milligan D, Clark RE; UK NCRI AML Study Group: A randomized comparison of daunorubicin $90 \mathrm{mg} / \mathrm{m}^{2} v s .60 \mathrm{mg} / \mathrm{m}^{2}$ in AML induction: results from the UK NCRI AML17 trial in 1206 patients. Blood 125: 3878-3885, 2015. PMID: 25833957. DOI: 10.1182/blood-2015-01-623447

8 Bradstock KF, Link E, Di Iulio J, Szer J, Marlton P, Wei AH, Enno A, Schwarer A, Lewis ID, D'Rozario, Coyle L, Cull G, Campbell P, Leahy MF, Hahn U, Cannell P, Tiley C, Lowenthal RM, Moore J, Cartwright K, Cunningham I, Taper J, Grigg A, Roberts AW, Benson W, Hertzberg M, Deveridge S, Rowlings P, Mills AK, Gill D, Bardy P, Campbell L, Seymour JF; Australasian Leukaemia and Lymphoma Group: Idarubicin dose escalation during consolidation therapy for adult acute myeloid leukemia. J Clin Oncol 35: 1678-1685, 2017. PMID: 28368672. DOI: $10.1200 / J C O .2016 .70 .6374$

9 Kim DS, Kang KW, Lee SR, Park Y, Sung HJ, Kim SJ, Choi CW and Kim BS: Comparison of consolidation strategies in acute myeloid leukemia: high-dose cytarabine alone versus intermediate-dose cytarabine combined with anthracyclines. Ann Hematol 94: 1485-1492, 2015. PMID: 25944346. DOI: 10.1007/ s00277-015-2389-9

10 Schaich M, Parmentier S, Kramer M, Illmer T, Stolzel F, Rollig C, Thiede C, Hanel M, Schafer-Eckart K, Aulitzky W, Einsele H, Ho AD, Serve H, Berdel WE, Mayer J, Schmitz N, Krause SW, Neubauer A, Baldus CD, Schetelig J, Bornhäuser M and Ehninger G: High-dose cytarabine consolidation with or without additional amsacrine and mitoxantrone in acute myeloid leukemia: results of the prospective randomized AML2003 trial. J Clin Oncol 31: 20942102, 2013. PMID: 23630210. DOI: 10.1200/JCO.2012.46.4743

11 Miyawaki S, Ohtake S, Fujisawa S, Kiyoi H, Shinagawa K, Usui N, Sakura T, Miyamura K, Nakaseko C, Miyazaki Y, Fujieda A, Nagai T, Yamane T, Taniwaki M, Takahashi M, Yagasaki F, Kimura Y, Asou N, Sakamaki H, Handa H, Honda S, Ohnishi K, Naoe $\mathrm{T}$ and Ohno R: A randomized comparison of 4 courses of standard-dose multiagent chemotherapy versus 3 courses of highdose cytarabine alone in postremission therapy for acute myeloid leukemia in adults: the JALSG AML201 Study. Blood 117: 23662372, 2011. PMID: 21190996. DOI: 10.1182/blood-2010-07295279

12 Yeshurun M, Labopin M, Blaise D, Cornelissen JJ, Sengeloev H, Vindelov L, Kuball J, Chevallier P, Craddock C, Socie G, Bilger K, Schouten HC, Fegueux N, Goker H, Maertens J, Bunjes D, Arnold R, Nagler A and Mohty M: Impact of postremission consolidation chemotherapy on outcome after reduced-intensity conditioning allogeneic stem cell transplantation for patients with acute myeloid leukemia in first complete remission: A report from the Acute Leukemia Working Party of the European Group for Blood and Marrow Transplantation. Cancer 120: 855-863, 2014. PMID: 24338939. DOI: $10.1002 /$ cncr.28498

13 McCormack SE, Cao Q, Oran B, Weisdorf DJ and Warlick ED: Pre-transplant consolidation chemotherapy may not improve outcomes after reduced intensity conditioning hematopoietic stem cell transplantation for acute myeloid leukemia in first complete remission. Leuk Res 35: 757-761, 2011. PMID: 21232793. DOI: 10.1016/j.leukres.2010.12.013

14 Tallman MS, Rowlings PA, Milone G, Zhang MJ, Perez WS, Weisdorf D, Keating A, Gale RP, Geller RB, Laughlin MJ, Lazarus HM, Luger SM, McCarthy PL, Rowe JM, Saez RA, Vowels MR and Horowitz MM: Effect of postremission chemotherapy before human leukocyte antigen-identical sibling transplantation for acute myelogenous leukemia in first complete remission. Blood 96: 1254-1258, 2000. PMID: 10942365.

15 Vardiman JW, Thiele J, Arber DA, Brunning RD, Borowitz MJ, Porwit A, Harris NL, Le Beau MM, Hellstrom-Lindberg E, Tefferi A and Bloomfield CD: The 2008 revision of the World Health Organization (WHO) Classification of Myeloid Neoplasms and Acute Leukemia: Rationale and important changes. Blood 114: 937-951, 2009. PMID: 19357394. DOI: 10.1182/blood-2009-03209262

16 Simons A, Shaffer LG and Hastings RJ: Cytogenetic Nomenclature: Changes in the ISCN 2013 Compared to the 2009 Edition. Cytogenet Genome Res 141: 1-6, 2013. PMID: 23817294. DOI: $10.1159 / 000353118$

17 Slovak ML, Kopecky KJ, Cassileth PA, Harrington DH, Theil KS, Mohamed A, Paietta E, Willman CL, Head DR, Rowe JM, Forman SJ and Appelbaum FR: Karyotypic analysis predicts outcome of preremission and postremission therapy in adult acute myeloid leukemia: A Southwest Oncology Group/Eastern Cooperative Oncology Group Study. Blood 96: 4075-4083, 2000. PMID: 11110676.

18 NCCN Guidelines for Acute Myeloid Leukemia. Available from: https://www.nccn.or g/professionals/physician_gls/pdf/aml.pdf

19 Warlick ED, Paulson K, Brazauskas R, Zhong X, Miller AM, Camitta BM, George B, Savani BN, Ustun C, Marks DI, Waller EK, Baron F, Freytes CO, Socie G, Akpek G, Schouten HC, Lazarus HM, Horwitz EM, Koreth J, Cahn JY, Bornhauser M, Seftel M, Cairo MS, Laughlin MJ, Sabloff M, Ringdén O, Gale RP, Kamble RT, Vij R, Gergis U, Mathews V, Saber W, Chen YB, Liesveld JL, Cutler CS, Ghobadi A, Uy GL, Eapen M, Weisdorf DJ and Litzow MR: Effect of postremission therapy before reduced-intensity conditioning allogeneic transplantation for acute myeloid leukemia in first complete remission. Biol Blood Marrow Transplant 20: 202-208, 2014. PMID: 24184335. DOI: 10.1016/j.bbmt.2013.10.023

20 Choi EJ, Lee JH, Lee JH, Park HS, Ko SH, Hur EH, Moon J, Goo BK, Kim Y, Seol M, Lee YS, Kang YA, Jeon M, Woo JM and Lee $\mathrm{KH}$ : Comparison of anthracyclines used for induction chemotherapy in patients with FLT3-ITD-mutated acute myeloid leukemia. Leuk Res 68: 51-56, 2018. PMID: 29544132. DOI: 10.1016/j.leukres.2018.03.006

Received August 19, 2019

Revised September 4, 2019

Accepted September 10, 2019 